\title{
Maternal Serum Lipids in Pre-Eclamptic and Normotensive Pregnant Women: A Case-Control Study
}

\author{
Olumide Emmanuel Adewara ${ }^{*}$, Adeleye Niyi Ogundolire ${ }^{2}$, Adebayo Augustine Adeniyi ${ }^{1}$, \\ Segun Murtala Ghazali ${ }^{3}$, Sunday Babatunde Awoyinka1, Idowu Adebara1, \\ Olumide Mojisola Ayankunle1, Ayokunle Moses Olumodeji', Olabisi Timothy Adeyemo', \\ Adewumi Bakare ${ }^{1}$
}

\author{
${ }^{1}$ Department of Obstetrics and Gynaecology, Afe Babalola University, Ado-Ekiti, Ekiti State, Nigeria \\ ${ }^{2}$ Department of Obstetrics and Gynaecology, Federal Teaching Hospital, Ido-Ekiti, Ekiti State, Nigeria \\ ${ }^{3}$ Department of Chemical Pathology, Afe Babalola University, Ado-Ekiti, Ekiti State, Nigeria \\ ${ }^{4}$ Department of Obstetrics and Gynaecology, Lagos State University Teaching Hospital, Ikeja, Lagos State, Nigeria \\ Email: *adewaraoe@abuad.edu.ng
}

How to cite this paper: Adewara, O.E., Ogundolire, A.N., Adeniyi, A.A., Ghazali, S.M., Awoyinka, S.B., Adebara, I., Ayankunle, O.M., Olumodeji, A.M., Adeyemo, O.T. and Bakare, A. (2021) Maternal Serum Lipids in Pre-Eclamptic and Normotensive Pregnant Women: A Case-Control Study. Open Journal of Obstetrics and Gynecology, 11, 1619-1628.

https://doi.org/10.4236/ojog.2021.1111151

Received: October 11, 2021

Accepted: November 22, 2021

Published: November 25, 2021

Copyright $\odot 2021$ by author(s) and Scientific Research Publishing Inc. This work is licensed under the Creative Commons Attribution International License (CC BY 4.0).

http://creativecommons.org/licenses/by/4.0/ (c) (i) Open Access

\begin{abstract}
Background: Preeclampsia-eclampsia is a major contributor to maternal and fetal, morbidity and mortality especially in low to middle income countries. This hypertensive disorder of pregnancy remains a disease of theories due to its unclear etiology. We evaluated for possible associations between maternal serum lipids and preeclampsia. Methods: This was a prospective case-control study that recruited 60 consenting women diagnosed with preeclampsia (cases) and 60 normotensive healthy pregnant women (controls), matched for maternal age and gestational age over an 8-month period ( $18^{\text {th }}$ June, 2014 to $18^{\text {th }}$ February, 2015) at the Federal Teaching Hospital Ido-Ekiti, Nigeria. Cases and controls were recruited using the non-probability convenience sampling. Fasting venous blood samples were collected in both cases and controls and analyzed for serum total cholesterol (TC), triglycerides (TG), high density lipoproteins (HDL) and low density lipoproteins (LDL) using Randox standard enzymatic methods. Data obtained were analyzed using SPSS version 18 to compare and test for significance using Student t-test, Chi-square, and Pearson's correlation as the appropriate. Tests of association were determined using logistic regression models. The difference was considered significant at $\mathrm{P}<0.05$. Findings: The mean serum levels of TC, HDL and LDL were significantly $(\mathrm{p}<0.001)$ higher in the pre-eclamptics $(6.6 \pm 2.9 \mathrm{mmol} / \mathrm{L}$, $2.1 \pm 1.0 \mathrm{mmol} / \mathrm{L}$ and $3.6 \pm 2.6 \mathrm{mmol} / \mathrm{L})$ than in normotensive women $(4.5 \pm$ $1.3 \mathrm{mmol} / \mathrm{L}, 1.5 \pm 0.9 \mathrm{mmol} / \mathrm{L}$ and $2.2 \pm 1.2 \mathrm{mmol} / \mathrm{L}$ ) respectively. Mean serum level of triglycerides was increased in the pre-eclamptics $(2.0 \pm 1.0$
\end{abstract}


$\mathrm{mmol} / \mathrm{L})$ compared to the controls $(1.8 \pm 0.6 \mathrm{mmo} / \mathrm{L})(\mathrm{p}=0.089)$. Serum TC, TG and LDL were similar in women with mild preeclampsia when compared with women with severe preeclampsia. Correlation between maternal systolic and diastolic blood pressures and the serum lipids was not significant. Adjusted multivariate logistic regression analysis revealed that total cholesterol $(\mathrm{OR}=4.363,95 \% \mathrm{CI}=1.410-13.506, \mathrm{p}=0.011)$ and high density lipoproteins $(\mathrm{OR}=3.247,95 \% \mathrm{CI}=1.086-9.709, \mathrm{p}=0.035)$ are significant independent risk factors for preeclampsia. Conclusion: Elevated maternal serum lipids are associated with preeclampsia, however, the widespread lack of uniformity in the patterns of dyslipidemias in pre-eclamptics, across different populations, may suggest that serum lipids will not be a reliable predictor or severity marker of preeclampsia.

\section{Keywords}

Pregnancy and Serum Lipids, Serum Lipids and Preeclampsia, Preeclampsia

\section{Introduction}

Preeclampsia is a multi-systemic disorder that is peculiar to human pregnancy [1]. It is characterized by the occurrence of hypertension and significant proteinuria after the $20^{\text {th }}$ week of gestation in a previously normotensive and non-proteinuric woman [1] [2]. It complicates $5 \%-7 \%$ of pregnancies [1] [3]. It is one of the leading causes of maternal and perinatal morbidity and mortality [1] [2]. It is a complex disorder characterized by generalized vasospasm, intravascular volume contraction, reduced organ perfusion and activation of coagulation cascade. It precedes the onset of eclampsia in most cases [4] [5].

The aetiology of preeclampsia is still unknown almost a century after it was termed the disease of theories [5] [6]. However, several aspects of its pathology are clearer and can now be related to its clinical manifestation [7] [8].

Some reports have suggested that women likely to develop preeclampsia have marked increase in serum triglycerides, free fatty acids and low density lipoprotein concentration, which are evident as early as 16 - 18 weeks gestation [9] [10]. These low density lipoproteins (LDL) are more susceptible to oxidative modification and it is the generation of oxidative stress and in turn Reactive Oxygen Species (ROS) that is thought to be responsible for the cycle of events, which causes the vascular endothelial damage [10] [11]. In addition, altered lipid metabolism and synthesis have been shown to lead to a decrease in the prostaglandin $\mathrm{I}_{2}$ : Thromboxane $\mathrm{A}_{2}$ ratio, which plays important contributory roles in the pathogenesis of preeclampsia. Studies among Caucasian women have suggested that maternal predisposition to preeclampsia may be linked with abnormal lipid metabolism [6] [9]. We therefore evaluated for associations between maternal serum lipids and preeclampsia in a black rural Nigerian population, where related studies are currently sparse. 


\section{Materials and Methods}

This was a hospital-based, prospective, case-control study in the Obstetrics and Gynaecology department of the Federal Teaching Hospital Ido-Ekiti, Nigeria, over an 8-month period (18 $8^{\text {th }}$ June, 2014 to $18^{\text {th }}$ February, 2015). Sixty consenting women with singleton pregnancy diagnosed with preeclampsia were recruited as cases and 60 normotensive, matched for maternal age and gestational age were recruited as controls. Both cases and controls were recruited using the non-probability convenience sampling from women receiving care in the study location.

Women with any of the following conditions; hepatic disease, acute or chronic infection, suspected fetal congenital abnormalities, multiple gestation, diabetes mellitus, pre-existing hypertension or other cardiovascular diseases, thyrotoxicosis, chronic renal disease and women on drugs that could influence serum lipid levels were excluded from the study.

The diagnosis of preeclampsia was made when the blood pressure of the pregnant woman was $140 / 90 \mathrm{mmHg}$ or more taken twice at least 4 hours apart with proteinuria of $2+$ or more on urinalysis, after 20 weeks gestational age in a previously normotensive and non-proteinuric woman. Preeclampsia was classified as mild or severe. Mild preeclampsia was when the systolic blood pressure was $\geq 140 \mathrm{mmHg}$ but $<160 \mathrm{mmHg}$ and diastolic blood pressure was $\geq 90 \mathrm{mmHg}$ but $<110 \mathrm{mmHg}$. Severe preeclampsia was diagnosed when the systolic blood pressure was $\geq 160 \mathrm{mmHg}$ and diastolic blood pressure was $\geq 110 \mathrm{mmHg}$ [1] [8]. Women who had features of HELLP syndrome (Haemolysis, Elevated Liver enzymes, and Low Platelets), oliguria ( $<400 \mathrm{ml} / 24$ hour), cerebral and visual disturbances, pulmonary oedema, cyanosis, epigastric and right upper quadrant pain were classified as severe preeclampsia [8] [12] [13].

Blood samples were drawn on presentation to the hospital after 8 - 12 hours of fasting and analyzed for serum Total cholesterol (TC), LDL-cholesterol, Triglycerides (TG) and HDL-cholesterol using enzymatic estimation kits for Total Cholesterol, LDL-cholesterol, HDL-cholesterol and Triglycerides manufactured by Randox Laboratories Limited, United Kingdom [14]. The study reference ranges were Total Cholesterol ( $\leq 5.2 \mathrm{mmol} / \mathrm{L})$, Triglycerides $(0.5-1.7 \mathrm{mmol} / \mathrm{L})$, HDL-cholesterol (1.1 - $1.7 \mathrm{mmol} / \mathrm{L})$ and LDL-cholesterol ( $\leq 2.3 \mathrm{mmol} / \mathrm{L})$.

Data were obtained and documented with the aid of a semi-structured proforma designed for the study and analyzed using International Business Machines (IBM) statistical package for social science (SPSS) version 18 (New York, USA). Variables were presented in frequency, percentages, means and standard deviation. The mean of two continuous variables were compared using independent Student t-test. Probability value ( $\mathrm{p}$-value) less than 0.05 was deemed significant. Pearson correlation coefficient was used to assess correlation between two continuous variables and tests of association were determined using logistic regression models. Ethical approval was obtained from the Health Research and Ethics Committee of the Federal Teaching Hospital Ido-Ekiti. 


\section{Results}

Sixty (60) consenting women with preeclampsia and 60 normotensive healthy pregnant women had their serum total cholesterol, LDL, HDL and triglycerides determined. The mean age of the pre-eclamptic group was $32.2 \pm 5.9$ years, while that of the normotensive group was $31.0 \pm 4.2$ years $(\mathrm{p}=0.190)$ (Table 1$)$. Majority $(85 \%)$ of the women with preeclampsia had some form of formal education while almost all the women (96.7\%) in the control group had formal education ( $\mathrm{p}<0.001$ ) (Table 1 ). The occupational distribution pattern between the two groups was similar, less than half of the cases $(41.7 \%)$ and one-fifth of the controls $(20 \%)$ were unemployed $(\mathrm{p}=0.057)($ Table 1$)$.

Table 1. Comparison of socio-demographic characteristics of the study population.

\begin{tabular}{|c|c|c|c|c|}
\hline \multirow{2}{*}{ Characteristics } & Controls & Preeclampsia & \multirow{2}{*}{$\chi^{2}$} & \multirow{2}{*}{$\mathrm{p}$-value } \\
\hline & $(n=60)$ & $(n=60)$ & & \\
\hline Age (years) & $n(\%)$ & $n(\%)$ & & \\
\hline$\leq 19$ & $0(0.0)$ & $2(3.3)$ & 10.366 & $0.024^{* *}$ \\
\hline $20-24$ & $5(8.3)$ & $5(8.3)$ & & \\
\hline $25-29$ & $16(26.7)$ & $8(13.3)$ & & \\
\hline $30-34$ & $29(48.3)$ & $22(36.7)$ & & \\
\hline$\geq 35$ & $10(16.7)$ & $23(38.4)$ & & \\
\hline Mean \pm SD & $31.0 \pm 4.2$ & $32.2 \pm 5.9$ & -1.319 & $0.190^{*}$ \\
\hline \multicolumn{5}{|l|}{ Marital status } \\
\hline Single & $4(6.7)$ & $13(21.7)$ & 5.551 & 0.018 \\
\hline Married & $56(93.3)$ & $47(78.3)$ & & \\
\hline \multicolumn{5}{|l|}{ Ethnicity } \\
\hline Yoruba & $50(83.3)$ & $42(70.0)$ & & $0.379^{* *}$ \\
\hline Ibo & $7(11.7)$ & $11(18.3)$ & & \\
\hline Hausa & $2(3.3)$ & $5(8.3)$ & & \\
\hline Others & $1(1.7)$ & $2(3.3)$ & & \\
\hline \multicolumn{5}{|l|}{ Education } \\
\hline None & $2(3.3)$ & $9(15.0)$ & 17.852 & $<0.001^{* *}$ \\
\hline Primary & $1(1.7)$ & $6(10.0)$ & & \\
\hline Secondary & $12(20.0)$ & $22(36.7)$ & & \\
\hline Tertiary & $45(75.0)$ & $23(38.3)$ & & \\
\hline \multicolumn{5}{|l|}{ Occupation } \\
\hline Civil servants & $31(51.7)$ & $19(31.7)$ & 7.538 & 0.057 \\
\hline Traders & $11(18.3)$ & $11(18.3)$ & & \\
\hline Self-employed & $6(10.0)$ & $5(8.3)$ & & \\
\hline Unemployed & $12(20.0)$ & $25(41.7)$ & & \\
\hline
\end{tabular}

$\chi^{2}$ Chi square statistic; ${ }^{\star}$ Student $t$ test; ${ }^{\star \star}$ Fisher's exact test; SD: Standard deviation. 
Table 2 shows that the mean systolic and diastolic blood pressure at the time of recruitment was $162.5 \pm 17.4 \mathrm{mmHg}$ and $105.7 \pm 13.2 \mathrm{mmHg}$ respectively in the women with preeclampsia and $107.1 \pm 10.3 \mathrm{mmHg}$ and $66.0 \pm 9.6 \mathrm{mmHg}$ respectively in the normotensive controls. There was no statistically significant difference in maternal weight between the preeclamptic cases $(72.8 \pm 13.0 \mathrm{~kg})$ and normotensive controls $(72.5 \pm 11.4 \mathrm{~kg})(\mathrm{p}=0.914)$. About two-third $(68.3 \%)$ of women with preeclampsia were unbooked compared to one-tenth (10\%) in the control group $(\mathrm{p}<0.001)$ (Table 2). Almost three-quarters $(71.7 \%)$ of the pre-eclamptic women were primigravidae compared to less than one-quarter (23.3\%) of the controls $(\mathrm{p}<0.001)$. The mean parity for the case and control group was $0.5 \pm 1.0$ and $1.3 \pm 1.1$ respectively $(\mathrm{p}<0.001)$ (Table 2$)$.

The mean serum total cholesterol, HDL and LDL in preeclamptics $(6.6 \pm 2.9$ $\mathrm{mmol} / \mathrm{L}, 2.1 \pm 1.0 \mathrm{mmol} / \mathrm{L}$ and $3.6 \pm 2.6 \mathrm{mmol} / \mathrm{L}$ respectively) were significantly higher than in controls $(4.5 \pm 1.3 \mathrm{mmol} / \mathrm{L}, 1.5 \pm 0.9 \mathrm{mmol} / \mathrm{L}$ and $2.2 \pm 1.2$ $\mathrm{mmol} / \mathrm{L}$ respectively) $(\mathrm{p}<0.001)$ (Table 3$)$. Mean serum level of triglycerides was higher in the preeclamptic group $(2.0 \pm 1.0 \mathrm{mmol} / \mathrm{L})$ than in controls $(1.8 \pm$ $0.6 \mathrm{mmo} / \mathrm{L})(\mathrm{p}=0.089)($ Table 3$)$. Serum HDL was lower in women with severe preeclampsia $(1.8 \pm 0.4 \mathrm{mmol} / \mathrm{L})$ than in women with mild preeclampsia $(2.2 \pm$ $1.0 \mathrm{mmol} / \mathrm{L})(\mathrm{p}=0.047)($ Table 4$)$.

Table 2. Clinical and obstetric characteristics of the women.

\begin{tabular}{|c|c|c|c|c|}
\hline \multirow{2}{*}{ Variables } & Controls & Preeclampsia & \multirow{2}{*}{$\mathrm{T}$} & \multirow{2}{*}{$\mathrm{p}$-value } \\
\hline & $(n=60)$ & $(n=60)$ & & \\
\hline Mean SBP (mmHg) & $107.1 \pm 10.3$ & $162.5 \pm 17.4$ & -21.172 & $<0.001$ \\
\hline Mean DBP (mmHg) & $66.0 \pm 9.6$ & $105.7 \pm 13.2$ & -18.863 & $<0.001$ \\
\hline \multicolumn{5}{|l|}{ Proteinuria } \\
\hline Yes & $0(0.0)$ & $60(100.0)$ & & $<0.001^{*}$ \\
\hline No & $60(100.0)$ & $0(0.0)$ & & \\
\hline Mean Weight (Kg) & $72.5 \pm 11.4$ & $72.8 \pm 13.0$ & -0.108 & 0.914 \\
\hline \multicolumn{5}{|l|}{ Gestational Age (wks) } \\
\hline$<28$ & $5(8.3)$ & $1(1.7)$ & & \\
\hline $28-36$ & $26(43.3)$ & $31(51.7)$ & & $0.217^{*}$ \\
\hline$>36$ & $29(48.4)$ & $28(46.7)$ & & \\
\hline Mean GA (wks) & $35.3 \pm 4.2$ & $35.3 \pm 3.8$ & -0.068 & 0.946 \\
\hline \multicolumn{5}{|l|}{ Booking status $n(\%)$} \\
\hline Booked & $54(90.0)$ & $19(31.7)$ & 42.845 & $<0.001^{* *}$ \\
\hline Unbooked & $6(10.0)$ & $41(68.3)$ & & \\
\hline \multicolumn{5}{|l|}{ Parity $n(\%)$} \\
\hline Nulliparous & $14(23.3)$ & $43(71.7)$ & & $<0.001^{*}$ \\
\hline $1-4$ & $45(75.0)$ & $13(21.7)$ & & \\
\hline 5 and above & $1(1.7)$ & $4(6.6)$ & & \\
\hline Mean parity & $1.3 \pm 1.1$ & $0.5 \pm 1.0$ & 4.102 & $<0.001$ \\
\hline
\end{tabular}

${ }^{\star}$ Fisher's exact test; ${ }^{* \star}$ Chi-square test; GA: Gestational age; wks: weeks. 
Table 3. Comparison of serum lipid in pre-eclamptic and normotensive women.

\begin{tabular}{ccccc}
\hline Serum Lipids & Controls & Preeclampsia & \multirow{2}{*}{$\mathrm{t}$} & p-value \\
\cline { 2 - 3 } & $(\mathrm{n}=60)$ & $(\mathrm{n}=60)$ & & \\
\hline TC (mmol/L) & $4.5 \pm 1.3$ & $6.6 \pm 2.9$ & -5.026 & $<0.001$ \\
TG (mmol/L) & $1.8 \pm 0.6$ & $2.0 \pm 1.0$ & -1.717 & 0.089 \\
HDL (mmol/L) & $1.5 \pm 0.9$ & $2.1 \pm 1.0$ & -3.862 & $<0.001$ \\
LDL (mmol/L) & $2.2 \pm 1.2$ & $3.6 \pm 2.6$ & -3.611 & $<0.001$ \\
\hline
\end{tabular}

t: student t-test; TC: Total Cholesterol; TG: Triglycerides; HDL: High Density Lipoprotein; LDL: Low Density Lipoprotein.

Table 4. Comparison of serum lipid among mild and severe pre-eclamptic women.

\begin{tabular}{cccccc}
\hline & Mild & Severe & \multirow{2}{*}{$\mathrm{T}$} & p-value \\
\cline { 2 - 3 } Serum Lipids & $(\mathrm{n}=30)$ & $(\mathrm{n}=30)$ & & \\
\hline TC (mmol/L) & $6.4 \pm 3.5$ & $6.8 \pm 2.2$ & -0.625 & 0.534 \\
TG (mmol/L) & $1.8 \pm 0.5$ & $2.3 \pm 1.4$ & -1.642 & 0.106 \\
HDL (mmol/L) & $2.2 \pm 1.0$ & $1.8 \pm 0.4$ & 2.034 & 0.047 \\
LDL (mmol/L) & $3.4 \pm 3.0$ & $3.8 \pm 2.1$ & -0.603 & 0.549 \\
\hline
\end{tabular}

t: student t-test; TC: Total Cholesterol; TG: Triglycerides; HDL: High Density Lipoprotein; LDL: Low Density Lipoprotein.

Correlation between all serum lipid values and both systolic and diastolic blood pressure in preeclamptic and normotensive women were poor and non-significant (Table 5). Association between elevated individual lipid values and preeclampsia were evaluated by using univariate unadjusted and multivariate adjusted (adjusted for confounders; age, education, parity, booking status and marital status) logistic regression analysis as seen in Table 6. Table 7 shows association between elevated serum lipids and severe preeclampsia.

\section{Discussion}

In this study, we observed significant increases in the serum total cholesterol, high density lipoproteins and low density lipoproteins in women with preeclampsia compared to normotensive pregnant women (Table 3). While the mean serum triglycerides level in preeclamptics was higher than in normotensive pregnant women, this was not statistically significant. Singh et al. in a related work in India similarly found that women who developed preeclampsia had increased levels of total cholesterol, triglyceride, HDL and LDL concentrations as compared with pregnant women who remained normotensive [15]. Alahakoon et al. also demonstrated that maternal TG levels are increased in preeclampsia [16]. Some other studies have demonstrated that serum TG and free fatty acid concentrations increased approximately twofold in women with preeclampsia relative to uncomplicated pregnancies with no effect on total cholesterol, HDL, 
Table 5. Correlation between Serum Lipid and Blood pressure in cases and controls.

\begin{tabular}{ccccc}
\hline \multirow{2}{*}{ Variables } & \multicolumn{2}{c}{ Controls } & \multicolumn{2}{c}{ Preeclampsia } \\
\cline { 2 - 5 } & $\mathbf{r}$ & P-value & $\mathbf{R}$ & p-value \\
\hline SBP vs. & & & & \\
TC & -0.081 & 0.537 & 0.028 & 0.834 \\
TG & -0.003 & 0.983 & -0.010 & 0.937 \\
HDL & 0.003 & 0.981 & -0.001 & 0.994 \\
LDL & -0.094 & 0.477 & 0.124 & 0.344 \\
DBP vs. & & & & \\
TC & -0.070 & 0.595 & 0.076 & 0.565 \\
TG & 0.058 & 0.661 & 0.101 & 0.442 \\
HDL & -0.119 & 0.364 & -0.091 & 0.489 \\
LDL & 0.002 & 0.989 & 0.050 & 0.705 \\
\hline
\end{tabular}

r: Pearson correlation coefficient.

Table 6. Logistic regression showing association between preeclampsia and increased maternal serum lipids.

\begin{tabular}{ccccc}
\hline Variables & OR $(95 \%$ C.I. $)$ & P value & aOR $(95 \%$ C.I. $)$ & p value \\
\hline TC & $4.369(2.025-9.424)$ & $<0.001$ & $4.363(1.410-13.506)$ & 0.011 \\
TG & $1.397(0.681-2.865)$ & 0.362 & $2.142(0.715-6.419)$ & 0.174 \\
HDL & $2.413(1.159-5.023)$ & $\mathbf{0 . 0 1 9}$ & $3.247(1.086-9.709)$ & 0.035 \\
LDL & $2.591(1.240-5.412)$ & $\mathbf{0 . 0 1 1}$ & $2.735(0.903-8.280)$ & 0.075 \\
\hline
\end{tabular}

OR: odds ratio; C.I.: confidence interval; aOR: adjusted odds ratio (age, education, parity, booking status and marital status); TC: Total Cholesterol; TG: Triglycerides; HDL: High Density Lipoprotein; LDL: Low Density Lipoprotein.

Table 7. Logistic regression showing association between severity of pre-eclampsia and increased maternal serum lipid.

\begin{tabular}{ccccc}
\hline Variables & OR $(95 \%$ C.I. $)$ & P value & aOR $(95 \%$ C.I. $)$ & p value \\
\hline TC & $3.286(1.085-9.952)$ & 0.035 & $4.033(0.994-16.373)$ & 0.051 \\
TG & $0.874(0.316-2.418)$ & 0.795 & $0.683(0.208-2.243)$ & 0.530 \\
HDL & $0.654(0.229-1.864)$ & 0.427 & $0.599(0.179-2.002)$ & 0.405 \\
LDL & $2.406(0.816-7.095)$ & 0.111 & $2.072(0.582-7.378)$ & 0.261 \\
\hline
\end{tabular}

OR: odds ratio; C.I.: confidence interval; aOR: adjusted odds ratio (age, education, parity, booking status and marital status) TC: Total Cholesterol; TG: Triglycerides; HDL: High Density Lipoprotein; LDL: Low Density Lipoprotein.

and LDL [17] [18]. This is unlike our observation in this study and the reasons for these differences are unclear but may be attributable to racial, dietary and environmental differences.

The values of all four serum lipids in women with severe preeclampsia were 
higher when compared to the normotensive women and similarly, so when compared with women with mild preeclampsia except for HDL which was lower in women with severe preeclampsia than in women with mild preeclampsia (Table 3 and Table 4). This was similar to other studies which reported that; high serum total cholesterol, triglycerides, low density lipoproteins and reduced serum high density lipoprotein were associated with severe preeclampsia [19] [20]. However, some authors have reported no significant difference in serum lipid profile between normal, mild, and severe pre-eclamptic women [10]. Eman et al., also reported significant increase in only triglycerides with no change in other serum lipids [21].

We found positive but negligible and insignificant correlation between serum lipids and blood pressure in both the preeclamptic and normotensive groups (Table 5). This was similar to a study done in Ibadan, Nigeria [9].

The lipid profile and associated preeclampsia risk and risk of severe preeclampsia) were evaluated by using univariate unadjusted and multivariate adjusted (adjusted for age, education, parity, booking status and marital status) logistic regression analysis (Table 6 and Table 7). Following multivariate adjusted regression analysis, only serum total cholesterol and HDL were independently associated with preeclampsia (Table 6) however, none of the serum lipids was independently associated with developing severe preeclampsia (Table 7). This finding agreed with studies done in Ibadan and Indian hospitals [9] [15].

\section{Conclusion}

We therefore conclude that despite possible associations of elevated serum lipid values and preeclampsia, the widespread lack of uniformity in the patterns of dyslipidemias in preeclamptics, across different populations suggests that serum lipids may not be a reliable predictor or severity marker of preeclampsia. However, the finding on Triglyceride in this study will need further research.

\section{Conflicts of Interest}

The authors report no conflict of interest.

\section{References}

[1] Miller, D.A. (2013) Hypertension in Pregnancy. In: De Cherney, A.H., Nathan, L., Goodwin, T.M. and Roman, A.S., Eds., Current Diagnosis and Treatment, Obstetrics and Gynecology, 11th Edition, McGraw Hill Companies, New York, 454-464.

[2] Gifford, R.W., August, P.A., Cunningham, G., Green, L.A., Lindheimer, M.D., Sibai, B.M., et al. (2000) Report of the National High Blood Pressure Education Program Working Group on High Blood Pressure in Pregnancy. American Journal of Obstetrics and Gynecology, 18, 1-22.

[3] Winer, N. and Tsasaris, V. (2008) Latest Developments: Management and Treatment of Preeclampsia. Journal de Gynecologie, Obstetrique et Biologie de la Reproduction, 37, 5-15. https://doi.org/10.1016/j.jgyn.2007.09.008

[4] Landau, R. and Irion, O. (2005) Recent Data on the Physiopathology of Preeclamp- 
sia and Recommendations for Treatment. Revue Médicale Suisse, 1, 292-295.

[5] Noris, M., Perico, N. and Remuzzi, G. (2005) Mechanisms of Disease: Preeclampsia. Nature Clinical Practice Nephrology, 1, 98-114.

https://doi.org/10.1038/ncpneph0035

[6] Mütze, S., Rudnik-Schöneborn, S., Zerres, K. and Rath, W. (2008) Genes and the Preeclampsia Syndrome. Journal of Perinatal Medicine, 36, 38-58. https://doi.org/10.1515/JPM.2008.004

[7] Grill, S., Rusterholz, C., Zanetti-Dällenbach, R., Tercanli, S., Holzgreve, W., Hahn, S., et al. (2009) Potential Markers of Preeclampsia-A Review. Reproductive Biology and Endocrinology, 14, 7-70. https://doi.org/10.1186/1477-7827-7-70

[8] Sibai, B. (2003) Diagnosis and Management of Gestational Hypertension and Preeclampsia. Obstetrics \& Gynecology, 102, 181-192. https://doi.org/10.1016/S0029-7844(03)00475-7

[9] Irinyenikan, T.A., Arowojolu, A. and Olayemi, A. (2014) Comparative Study of Serum Lipid Levels in Normotensive and Pre-Eclamptic Nigerian Women. International Journal of Biomedical Research, 3, 137-145.

https://doi.org/10.14194/ijmbr.3.2.10

[10] Chanvitya, P. and Boonsri, K. (2008) Comparative Study of Serum Lipid Concentrations in Preeclampsia and Normal Pregnancy. Journal of the Medical Association of Thailand, 91, 57-61.

[11] Kupfermine, M.J., Peaceman, A.M., Aderka, D., Wallach, D. and Socol, M.L. (1996) Soluble Tumour Necrosis Factor Receptors and Interleukin-6 Levels in Patients with Severe Preeclampsia. Obstetrics \& Gynecology, 3, 420-427. https://doi.org/10.1016/0029-7844(96)00179-2

[12] Packer, C.S. (2005) Biochemical Markers and Physiological Parameters as Indices for Identifying Patients at Risk of Developing Preeclampsia. Journal of Hypertension, 23, 45-46. https://doi.org/10.1097/00004872-200501000-00011

[13] Kumar, C.A. and Das, U. (2002) Oxidant Stress in Preeclampsia and Essential Hypertension. Journal of the Association of Physicians of India, 50, 1372-1375.

[14] Randox Laboratories Limited, Manual/RX Monza. Total Cholesterol, HDL-Cholesterol and Triglyceride. Enzymatic Colorimetric Method Manual.

[15] Singh, U., Yadav, S., Mehrotra, S., Natu, S.M., Kumari, K. and Yadav, Y.S. (2013) Serum Lipid Profile in Early Pregnancy as a Predictor of Preeclampsia. International Journal of Medical Research and Review, 1, 55-54. https://doi.org/10.17511/ijmrr.2013.i02.03

[16] Alahakoon, T.I., Medbury, H.J., Williams, H., et al. (2020) Lipid Profiling in Maternal and Fetal Circulations in Preeclampsia and Fetal Growth Restriction-A Prospective Case Control Observational Study. BMC Pregnancy Childbirth, 20, 61. https://doi.org/10.1186/s12884-020-2753-1

[17] Hubel, C.A., McLaughlin, M.K., Evans, R.W., Hauth, B.A., Sims, C.J. and Roberts, J.M. (1996) Fasting Serum Triglycerides, Free Fatty Acids, and Malondialdehyde Are Increased in Preeclampsia, Are Positively Correlated, and Decrease within 48 Hours Post Partum. American Journal of Obstetrics and Gynecology, 174, 975-982. https://doi.org/10.1016/S0002-9378(96)70336-8

[18] Swapan, D., Debasish, C., Sanjay, S., Prakash, D., et al. (2013) Comparison of Lipid Profiles in Normal Pregnancy and in Preeclampsia. The Journal of Medical Sciences, 11, 53-55. https://doi.org/10.9790/0853-1145355

[19] Ray, J.G., Diamond, P., Singh, G. and Bell, C.M. (2006) Brief Overview of Maternal 
Triglycerides as a Risk Factor for Preeclampsia. BJOG, 113, 379-386. https://doi.org/10.1111/j.1471-0528.2006.00889.x

[20] Baksu, B., Baksu, A., Davas, I., Akyol, A. and Gulbaba, G. (2005) Lipoprotein(a) Levels in Women with Preeclampsia and in Normotensive Pregnant Women. Journal of Obstetrics and Gynaecology Research, 31, 277-282.

https://doi.org/10.1111/j.1447-0756.2005.00276.x

[21] Eman, C.K. and Ahlam, A.H. (2014) Lipid Profile and Preeclampsia. Qatar Medical Journal, 7, 260-271. 